\title{
Impact of $\mathrm{CuO}$ nanoleaves on MWCNTs/GCE nanocomposite film modified electrode for the electrochemical oxidation of folic acid
}

\author{
D. Manoj · D. Ranjith Kumar · J. Santhanalakshmi
}

Received: 5 November 2011/Accepted: 13 March 2012/Published online: 4 April 2012

(C) The Author(s) 2012. This article is published with open access at Springerlink.com

\begin{abstract}
The salient features of the present work focus on the synthesis of $\mathrm{CuO}$ nanoleaves by alcoholic reduction of $\mathrm{Cu}$ (II) chloride in the presence of poly(diallyldimethylammonium chloride) (PDDA) for the application of folic acid oxidation in simulated body fluid environment. PDDA-assisted polyol process allows a conventional impregnation method for the formation of $\mathrm{CuO}$ with welldefined leaf-like structure. The structure and morphology of the $\mathrm{CuO}$ nanoleaves were characterized by Fouriertransform infrared (FT-IR) spectroscopy and X-ray diffraction (XRD) analysis. Field emission scanning electron microscope (FESEM) image confirms the formations of $\mathrm{CuO}$ with leaf-like morphology and branched side edges. The average size of the resultant $\mathrm{CuO}$ nanoleaves was calculated to be $400 \mathrm{~nm}$ in length and $150 \mathrm{~nm}$ in width. The electrochemical performance of the CuONs/ MWCNTs/GCE nanocomposite modified electrode was characterized by cyclic voltammetric (CV) studies. The $\mathrm{CuONs} / \mathrm{MWCNTs} / \mathrm{GCE}$ nanocomposite modified electrode shows good electrochemical activity and it was also found that it possessed prominent electrocatalytic activity toward the oxidation of folic acid with as high a sensitivity as $3.35 \mu \mathrm{A} / \mu \mathrm{M}$ and a low detection limit $(3 \sigma)$ of $15.2 \mathrm{nM}$ $(\mathrm{S} / \mathrm{N}=3)$. Besides, the $\mathrm{CuO}$ nanocomposite modified electrode lowers the over potential of folic acid oxidation than the unmodified electrodes.
\end{abstract}

Keywords $\mathrm{CuO}$ nanoleaves $\cdot$ Multiwalled carbon nanotubes · Folic acid - Electrochemical oxidation - DPV

D. Manoj · D. Ranjith Kumar · J. Santhanalakshmi ( $\square)$

Department of Physical Chemistry, University of Madras,

Maraimalai Campus, Chennai 600 025, India

e-mail: jslakshmi@yahoo.co.in

\section{Introduction}

Folic acid, N-[p-\{[(2-amino-4-hydroxy-6-pteridinyl) methyl] amino\}benzoyl]-L-glutamic acid, a water-soluble vitamin (vitamin $\mathrm{B}_{9}$ ) and an essential nutrient, plays a significant role in the synthesis of purines and pyrimidines for DNA and in cell replication. Research over the past decade has shown that deficiency in folate concentration leads to neural tube defects in newborns and to an increased risk of megaloblastic anemia, cancer, coronary heart disease, Alzheimer's disease, neurological disorders, and cardiovascular disease in children and in adults (Choi and Mason 2000; Tallaksen et al. 1992; Reynolds 2006). Furthermore, the requirement of folate increases during the periods of rapid cell division and it is essential for pregnant women (Bailey and Gregory 1999). However, monitoring the amount of folic acid concentration at an appropriate level for human health is of higher demand. Therefore, the development of a simple, economical and accurate analytical method for the determination of folic acid in pharmaceutical and food samples is of great importance. The determination of folic acid can be carried out by using several techniques such as high-performance liquid chromatography (HPLC) (Osseyi et al. 1998), spectrophotometry (Andrisano et al. 2003), flow injection chemiluminescence (Zhang et al. 2008a) and fluorimetric method (Giron et al. 2008). However, these techniques consume a long time for analysis, are subject to interferences and require expensive reagents. These disadvantages do not make them applicable for rapid analytical determination.

In this context, electrochemical methods have the advantage of simplicity, and high sensitivity and selectivity making them suitable for the determination of folic acid. In recent years, numerous reports have been studied for the electrochemical determination and quantification of folic 
acid. Chemically modified electrodes have been widely used compared to the commercial glassy carbon electrode (GCE) to lower the overpotential. This is because of their high electron transfer rate, high sensitivity, selectivity and stability in analyzing the electrochemical behavior of folic acid. These include multi-walled carbon nanotubes modified gold electrode (Wei et al. 2006), single-wall carbon nanotube film (Wang et al. 2006), phosphomolybdicpolypyrrole film (Guo et al. 2006), calixarene (Vaze and Srivastava 2007), lead film (Korolczuk and Tyszczuk 2007), single-walled carbon nanotube-ionic liquid (Xiao et al. 2008), 5-amino-2-mercapto-1,3,4-thiadiazole film (Kalimuthu and John 2009), poly(brilliant cresyl blue) multiwall carbon-nanotube film (Umasankar et al. 2011) and mesoporous carbon (Yang et al. 2011) modified electrodes.

Recently, metal oxide nanostructures (nanorods, nanowires, nanotubes, nanosheets, nanoneedles, nanoribbons) have received significant interest owing to their large surface area with attractive optical and potential applications. Copper oxide (CuO), an important p-type semiconductor, an antiferromagnetic material and a high temperature $\left(T_{c}\right)$ superconductor with a narrow band gap of $E_{\mathrm{g}}=1.2 \mathrm{eV}$, has been studied extensively and used as a promising material for fabricating batteries (Poizot et al. 2000), magnetic storage media (Venkatachalam et al. 2009), solar cells (Liu et al. 2007) and biosensors (Zhang et al. 2008b). Therefore, considerable efforts have been developed toward the synthesis of $\mathrm{CuO}$ nanomaterials to enhance their existing applications. The properties of nanomaterials are size and morphological dependent and therefore these materials represented a fascinating route for the fabrication of nanostructured materials exhibiting great electrochemical performances (Xiang et al. 2010). The modification of an electrode by nanostructured materials is an essential way to enhance the selectivity and sensitivity of the electrochemical method. However, the fabrication of metal oxide nanostructures with well-defined shapes, by a simple and inexpensive route, remains a great challenge. Therefore, considerable effort has been taken toward the fabrication of inexpensive PDDA-stabilized $\mathrm{CuO}$ nanoleaves-incorporated MWCNTs/GCE nanocomposite film modified electrode to lower the overpotential for the electrochemical oxidation of folic acid and for the successful determination of folic acid.

\section{Experimental procedure}

Materials

Poly(diallyldimethyl)ammonium chloride (PDDA) $\left(M_{\mathrm{w}}=\right.$ $5,000-20,000,25 \mathrm{wt} \%$ in water), anhydrous copper (II) chloride and multiwalled carbon nanotubes (MWCNTs) were purchased from Sigma-Aldrich. Folic acid tablets were purchased from a local drug store. A standard phosphate buffer (PBS) (pH 7.0) solution prepared with $\mathrm{Na}_{2} \mathrm{HPO}_{4}$ and $\mathrm{NaH}_{2} \mathrm{PO}_{4}$ was used as the supporting electrolyte. All the other chemicals and reagents used in the experiments were of analytical grade and used without further purification. All the solutions were prepared using double-distilled (DD) water.

\section{Tablet sample preparation}

Five tablets ( $25 \mathrm{mg}$ folic acid per tablet) of folic acid pharmaceutical formulation were accurately weighed and finely ground in a mortar until a fine and homogeneous powder resulted. A stock solution of $0.01 \mathrm{M}$ folic acid was prepared in a $100-\mathrm{mL}$ standard flask with $0.1 \mathrm{M}$ PBS (pH-7.0) kept in dark under refrigeration (below $4{ }^{\circ} \mathrm{C}$ ).

\section{Synthesis of $\mathrm{CuO}$ nanoleaves}

In a typical method for the preparation of $\mathrm{CuO}$ nanoleaves, an appropriate amount of PDDA solution was mixed with ethanol/water (4:6 v/v) and then $0.01 \mathrm{M}$ aqueous $\mathrm{CuCl}_{2}$ was added dropwise into the solution with a molar ratio of 10:1. The $\mathrm{pH}$ of the reaction mixture was adjusted to 10.5 by adding $\mathrm{NaOH}$ and then the reaction mixture was heated to $60{ }^{\circ} \mathrm{C}$ for $1 \mathrm{~h}$ under nitrogen atmosphere. The color of the solution changed from yellow to dark brown indicating the reduction of $\mathrm{Cu}^{2+}$ ions and the formation of $\mathrm{CuO}$ nanostructures.

\section{Fabrication of CuONs/MWCNTs/GCE modified electrode}

$1 \mathrm{mg}$ of functionalized MWCNTs was dispersed in $1 \mathrm{~mL}$ of $(0.5 \%)$ ethanolic nafion solution and sonicated for 30 minutes to get a homogeneous black suspension (Tsai et al. 2005). The fabrication of MWCNTs/GCE was performed by casting $10 \mu \mathrm{L}$ of MWCNTs dispersion on the GCE surface and allowing to dry for 15 minute at room temperature. For the modification of $\mathrm{CuO} / \mathrm{MWCNTs} / \mathrm{GCE}$ modified electrode, $1.0 \mathrm{mg} / \mathrm{mL}$ solution of $\mathrm{CuO}$ nanocomposites was dispersed in ethanol and sonicated for few minutes and then $5 \mu \mathrm{L}$ of colloids was dropped onto the electrode surface and allowed to dry under ambient conditions.

\section{Characterization}

All the electrochemical measurements were performed on PGSTAT-12 electrochemical workstation (AUTOLAB, The Netherlands BV). The measurements were based on a 
three-electrode system, with a glassy carbon electrode (GCE) of geometric area $\left(0.07 \mathrm{~cm}^{2}\right)$, used as a working electrode, a Pt wire in the form of a spiral with high geometrical surface area $\left(\sim 20 \mathrm{~cm}^{2}\right)$ that served as the counter electrode and saturated calomel electrode (SCE) as the reference electrode. Prior to each experiment, the GCE surface was polished with increasingly finer grade alumina powders (1, 0.3 and 0.05 micron) down to mirror polish, sonicated for about 15 minute in double-distilled (DD) water, degreased with acetone and washed with copious amounts of DD water. All the solutions were purged with iolar $(99.9 \%$ purity) nitrogen for at least 30 minutes prior to each electrochemical measurement and a nitrogen environment was maintained throughout all the experiments.

FT-IR spectra were recorded by using BRUKER (TENSOR 27) in the region $4,000-400 \mathrm{~cm}^{-1}$ as $\mathrm{KBr}$ pellets. The morphology of the $\mathrm{CuO}$ nanoleaves was observed by utilizing a PHILIPS CM20 transmission electron microscope operated at an accelerating voltage of $200 \mathrm{kV}$. Field emission scanning electron microscopy (FESEM) images were obtained using a Hitachi SU6600. X-Ray diffraction (XRD) results were collected by using X-ray diffractometer (BRUKER D8 Advance) with monochromatic $\mathrm{Cu} \mathrm{K} \alpha$ radiation $(\lambda=1.5418 \AA)$.

\section{Results and discussion}

\section{FT-IR characterization}

Figure 1 compares the FT-IR spectra of the (a) pure PDDA and (b) PDDA-stabilized $\mathrm{CuO}$ nanoleaves. The peak observed at $3441 \mathrm{~cm}^{-1}$ corresponds to the $-\mathrm{OH}$ stretching frequency vibration of the $-\mathrm{H}_{2} \mathrm{O}$ group containing the PDDA molecule. The frequency of the $\mathrm{C}=\mathrm{C}$ stretching vibration experiences a shift of peak at $1,641-1,684 \mathrm{~cm}^{-1}$ with a decrease in the intensity due to interactions between PDDA and $\mathrm{CuO}$ nanoleaves. The appearance of two new peaks at 1,364 and $850 \mathrm{~cm}^{-1}$ (curve b) is assigned to $\mathrm{N}=\mathrm{O}$ and $\mathrm{C}-\mathrm{N}$ vibrations of the nitroso group produced after PDDA reacts with $\mathrm{CuCl}_{2}$. On comparing the PDDA with PDDA-stabilized $\mathrm{CuO}$ nanoleaves, the strong bands observed at 498, 423 and $608 \mathrm{~cm}^{-1}$ can be attributed to the $\mathrm{Cu}-\mathrm{O}$ stretching vibration of the monoclinic phase $\mathrm{CuO}$ (Zou et al. 2006). There is no peak at $615 \mathrm{~cm}^{-1}$ confirming the absence of $\mathrm{Cu}_{2} \mathrm{O}$ and indicating the formation of $\mathrm{CuO}$.

\section{XRD characterization}

Figure 2 depicts the typical XRD pattern of $\mathrm{CuO}$ nanoleaves. The strong diffraction peaks can be indexed as (110), (002), (200), (-202), (202), (-113), (311), (220) and (-222) corresponding to the $\mathrm{CuO}$. Compared with the standard

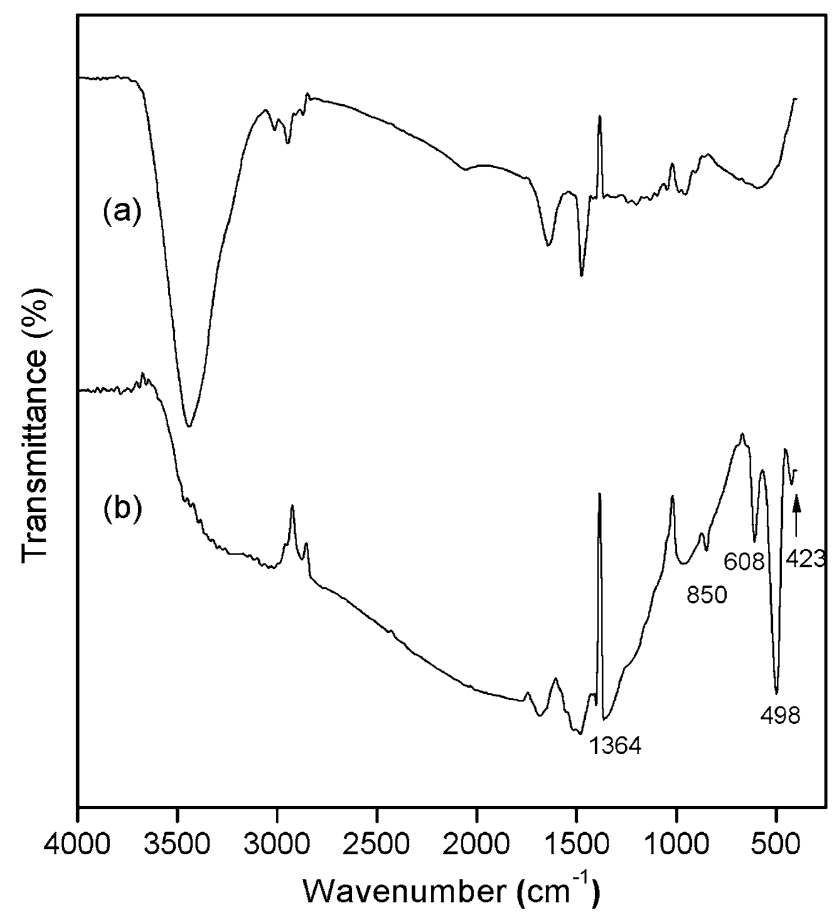

Fig. 1 FT-IR spectra of a pure PDDA and b PDDA-stabilized CuO nanoleaves

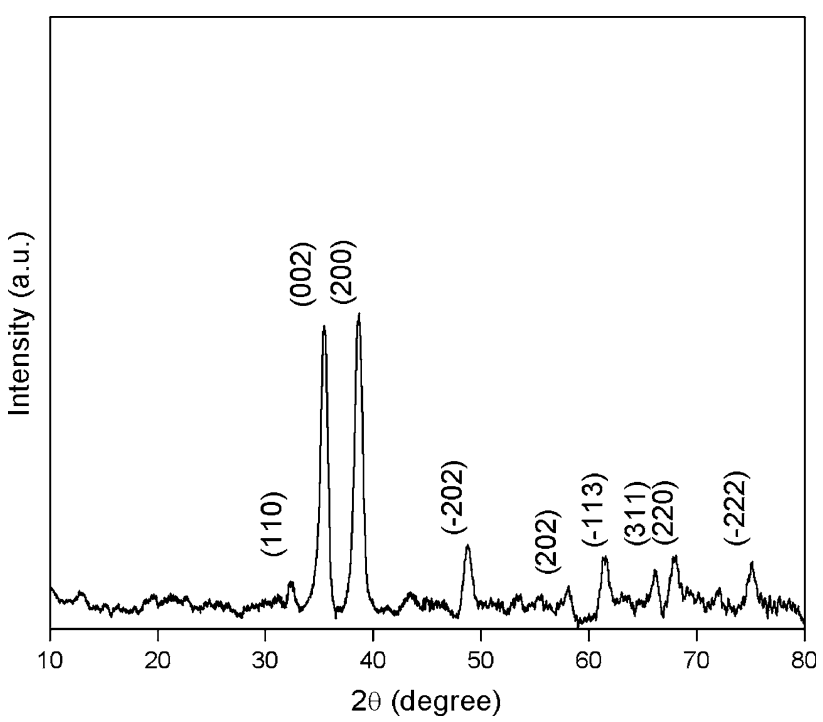

Fig. 2 XRD pattern of $\mathrm{CuO}$ nanoleaves

diffraction peak, there is no observation of impurity peaks such as $\mathrm{Cu}(\mathrm{OH})_{2}$, and $\mathrm{Cu}_{2} \mathrm{O}$ reveals the presence of pure $\mathrm{CuO}$ nanostructures only (Liu et al. 2005). The peak broadening of the XRD spectra indicated the nanoscale structural features of the $\mathrm{CuO}$ nanoleaves. The XRD results confirm the formation of monoclinic $\mathrm{CuO}$ structure $\left(a_{0}=4.1728 \AA, b_{0}=3.4301 \AA\right.$, $c_{0}=5.1261 \AA$ ) (JCPDS 89-2,529).

The chemical composition of the obtained $\mathrm{CuO}$ nanoleaves was determined using energy dispersive X-ray 


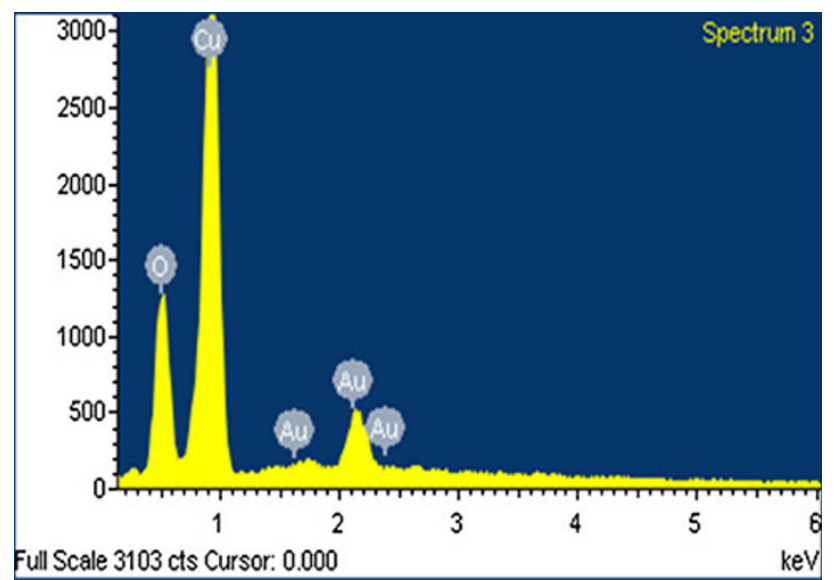

Fig. 3 EDAX spectrum of $\mathrm{CuO}$ nanoleaves
(EDAX) analysis. In the EDAX spectrum (Fig. 3), except for the Au signals (from gold coating), only peaks of $\mathrm{Cu}$ and $\mathrm{O}$ are observed which reveals that the obtained $\mathrm{CuO}$ nanoleaves are composed of $\mathrm{Cu}$ and $\mathrm{O}$ only.

Morphological studies

Figure $4 \mathrm{a}$ shows the FESEM image of $\mathrm{CuO}$ nanoleaves prepared using an alcohol thermal reduction showing high density growth of $\mathrm{CuO}$ nanoleaves with uniform sizes and an average size of $400 \mathrm{~nm}$ in length and $150 \mathrm{~nm}$ in width. Interestingly, we observed many $\mathrm{CuO}$ nanoleaves with branched side edges and it can be clearly seen in the magnified image (Fig. 4b). In addition, $\mathrm{CuO}$ nanorods are aligned parallel to each other along the axis facilitating the formation of nanoleaf just after completing a short growth
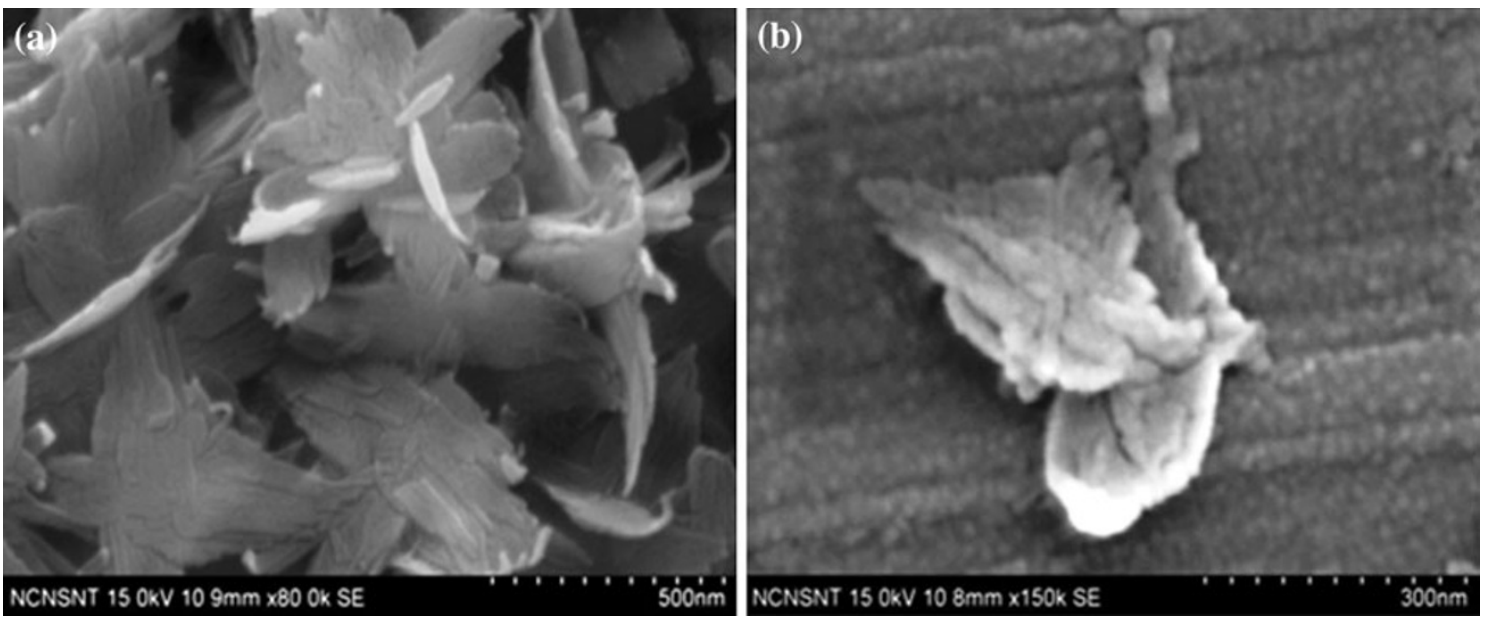

Fig. 4 FESEM image of a PDDA-stabilized $\mathrm{CuO}$ nanoleaves. b Magnified image of $\mathrm{CuO}$ nanoleaves
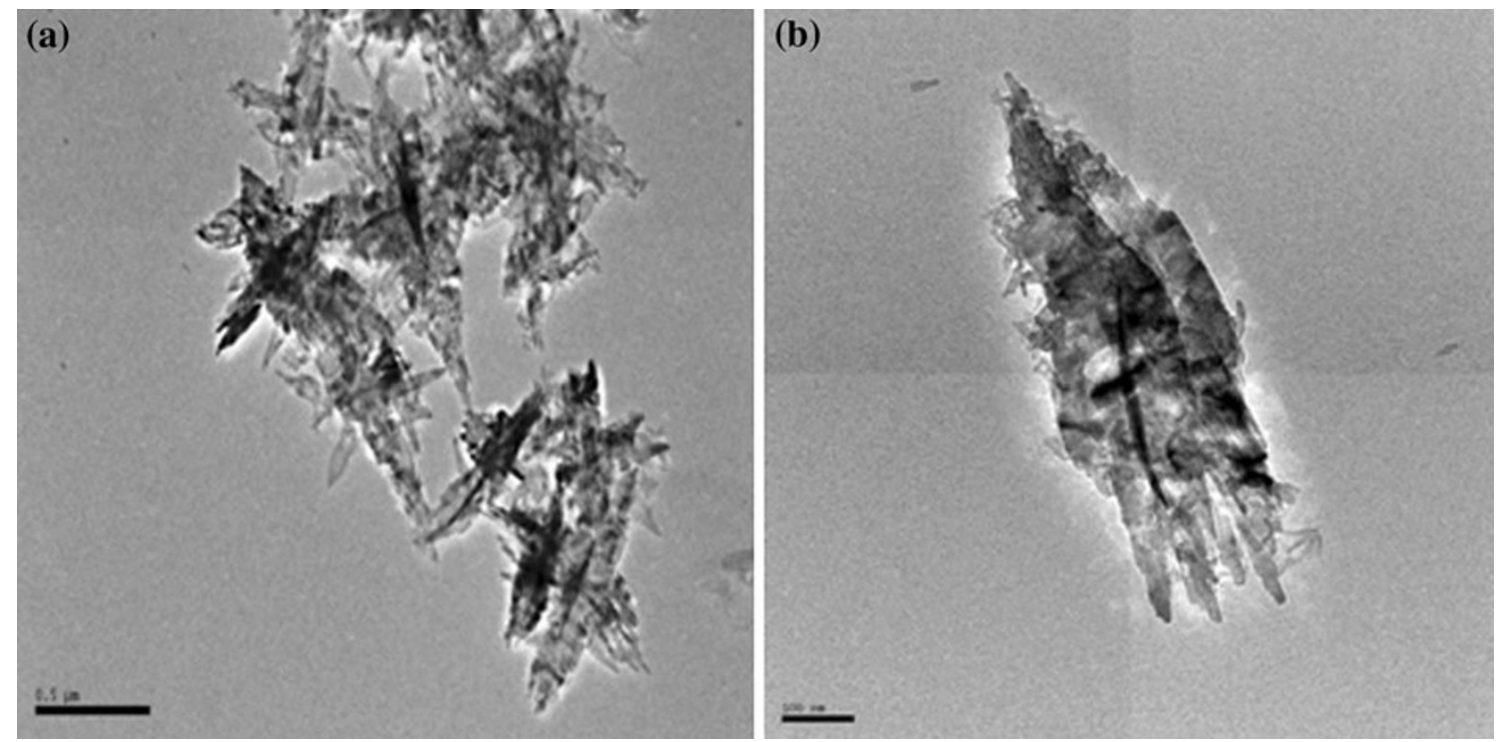

Fig. 5 HRTEM image of a PDDA-stabilized $\mathrm{CuO}$ nanoleaves. b Magnified image of $\mathrm{CuO}$ nanoleaves 
nucleation time in the reaction solution. Thus, it can be concluded that the $\mathrm{CuO}$ nanorods should be formed quickly at an early stage, followed by the assemblies of nanosized subunit building blocks which leads to formation of $\mathrm{CuO}$ nanoleaves by aggregation. To further confirm the structure and assembly of $\mathrm{CuO}$ nanoleaves, HRTEM image was taken for the individual nanoleaves. Fig. 5a shows the HRTEM image of the $\mathrm{CuO}$ nanoleaves, which accords well with the FESEM results, exhibiting the leaf-like morphology. Closer observation (Fig. 5b) reveals that the $\mathrm{CuO}$ nanoleaves are bundled together, indicating that these nanoleaves can form in a short nucleation time by selfassembly of the nanorods.

The mechanism for the formation of $\mathrm{CuO}$ nanoleaves are as follows: $\mathrm{CuCl}_{2}$ reacts with $\mathrm{NaOH}$ at $\mathrm{pH} 10.5$ and generates $\mathrm{OH}^{-}$to form copper hydroxide $\left(\mathrm{Cu}(\mathrm{OH})_{2}\right)$ in the solution. The concentration of $-\mathrm{OH}^{-}$can significantly affect the nucleation time and the growth of the $\mathrm{CuO}$ nanoleaves. Therefore, in this reaction the amount of $-\mathrm{OH}^{-}$plays an important role in the formation of $\mathrm{CuO}$ nanoleaves, because the $-\mathrm{OH}^{-}$is not only the reactant but also the product of the reaction. Furthermore, $\mathrm{Cu}(\mathrm{OH})_{2}$ reacts with two dissociative $\mathrm{OH}^{-}$ions to form an unstable intermediate $\mathrm{Cu}(\mathrm{OH})_{4}^{2-}$ and this intermediate liberates two $-\mathrm{OH}^{-}$ions resulting in the formation of $\mathrm{CuO}$ nanoleaves and this reaction is reversible and hence the basicity of the reaction is crucial (Zhao et al. 2011).

\section{Electrochemical oxidation of folic acid}

Figure 6 compares the electrochemical behavior of folic acid on $\mathrm{CuONs} / \mathrm{MWCNTs/GCE}, \mathrm{MWCNTs/GCE}$ and bare GCE modified electrode in the $0.1 \mathrm{M}$ PBS (pH-7.0)

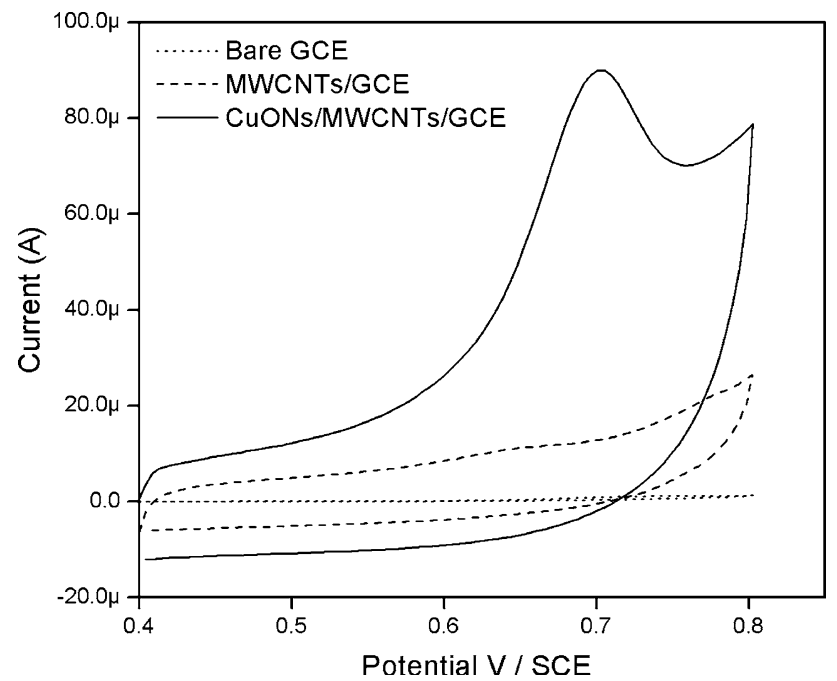

Fig. 6 Cyclic voltammogramms for $0.1 \mathrm{mM}$ folic acid in $0.1 \mathrm{PBS}$ ( $\mathrm{pH}$ 7.0) on CuONs/MWCNTs/GCE modified electrode (continuous line), MWCNTs/GCE modified electrode (dashed line) and bare GCE (dotted line) at a scan rate of $100 \mathrm{mV} \mathrm{s}^{-1}$ containing $0.1 \mathrm{mM}$ folic acid at a scan rate of $100 \mathrm{mV} \mathrm{s}^{-1}$ respectively. At the bare GCE (dotted line) there is no significant voltammetric response for folic acid. After loading MWCNTs on the electrode surface MWCNTs/ GCE (dashed line) modified electrode shows a small and undefined oxidation peak. The solid line shows the voltammetric response for $\mathrm{CuONs/MWCNTs/GCE} \mathrm{nano-}$ composite modified electrode in which the electrochemical oxidation of folic acid shows a well-defined oxidation peak at $+0.64 \mathrm{mV}$. Compared to bare GCE and MWCNTs/GCE a rapid increase in the anodic current was observed on CuONs/MWCNTs/GCE modified electrode which is attributed to an irreversible electrochemical oxidation of folic acid. The increase in the anodic peak current on CuONs/MWCNTs/GCE than MWCNTs/GCE modified electrode was due to the presence of $\mathrm{CuO}$ nanostructures of larger surface area responsible for the oxidation of folic acid. A considerable increase in the anodic peak current and sharpness in the anodic oxidation reflect that the CuONs/MWCNTs/GCE modified electrode facilitates the electrochemical oxidation of folic acid.

\section{Effect of scan rate}

The CuONs/MWCNTs/GCE nanocomposite modified electrode was placed in $0.1 \mathrm{mM}$ folic acid in the desired PBS (pH-7.0) solution and allowed to accumulate at open circuit potential for 1 minute. This procedure was used to evaluate the electrochemical determination of folic acid. To understand the nature of electrocatalytic process, the effect of scan rate on the electrocatalytic oxidation of folic acid was studied. Figure 7 depicts the cyclic voltammograms (CVs) of CuONs/MWCNTs/GCE modified electrode in $0.1 \mathrm{M}$ PBS ( $\mathrm{pH}-7.0$ ) containing $0.1 \mathrm{mM}$ folic acid at different scan rates ranging from 5 to $100 \mathrm{mV} \mathrm{s}^{-1}$. Figure 7 (Inset) shows the linear calibration plot in which the anodic peak current increases rapidly with increase in the scan rate. The oxidation peak current potential was shifted to more positive values with the increase of scan rate, which confirmed the irreversibility of the oxidation process of folic acid. Figure 7(a) shows the relationship between $\log \left(i_{\mathrm{p}}\right)$ and $\log (v)$ with a slope of 0.89 , indicating that the electron transfer is not under diffusion control which means that folic acid molecules remains adsorbed on the electrode surface.

Based on Laviron theory (Laviron 1978), the number of electron transfer $(n)$ involved in the CuONs/MWCNTs/GCE modified electrode could be determined using the Eq. (1)

$i_{\mathrm{p}}=n F Q v / 4 R T$

The value of $n$ has been obtained as 2, indicating the oxidation of folic acid as two electron transfer process. The plausible mechanism for folic acid oxidation at $\mathrm{CuO}$ / 


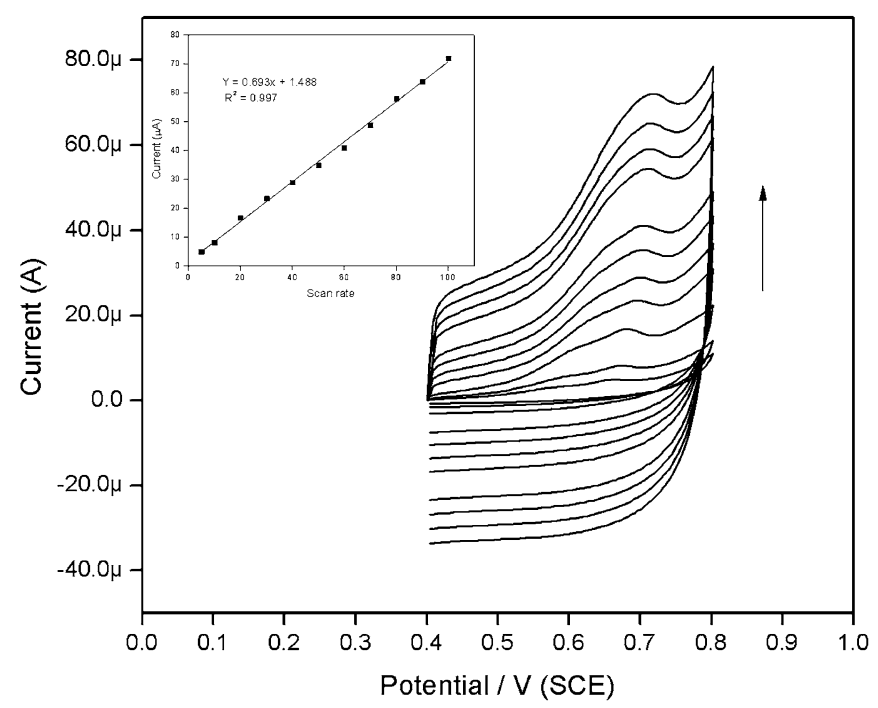

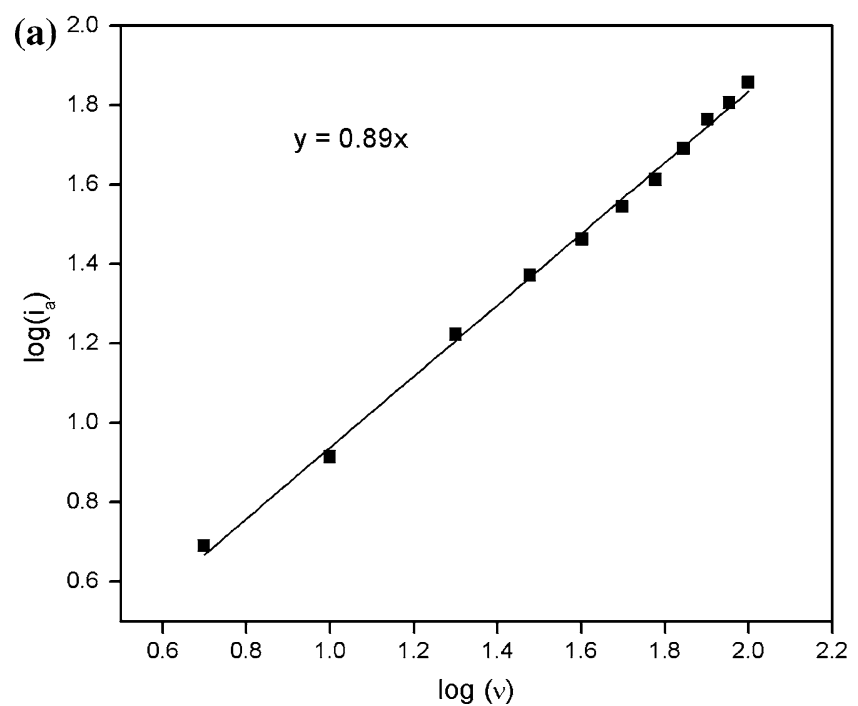

Fig. $7 \mathrm{CVs}$ of CuONs/MWCNTs/GCE modified electrode in $0.1 \mathrm{mM}$ folic acid (0.PBS $(\mathrm{pH} 7.0)$ ) at different scan rates from 5 to $100 \mathrm{mV} \mathrm{s}^{-1}$. Inset shows the calibration plot of peak current of

MWCNTs/GCE modified electrode is represented in scheme 1.

For an anodic process, the values of $\alpha$ and $k_{\mathrm{s}}$ were obtained as 0.4 and $3.8 \mathrm{~s}^{-1}$ from the slope and intercept of the linear calibration plot $E_{\mathrm{a}}$ versus $\log (v)$ according to the Eq. (2) as shown in Fig. 7(b).

$E_{\mathrm{a}}=0.045(\log v)+0.625\left(R^{2}=0.998\right)$

Amperometric determination of folic acid

Figure 8 shows the amperometric response of CuONs/ MWCNTs/GCE modified electrode on successive addition of $50 \mu \mathrm{L}$ of folic acid at the fixed potential of $+0.65 \mathrm{~V}$ in $0.1 \mathrm{M}$ PBS (pH-7.0) at a stirring rate of $300 \mathrm{rpm}$. The CuONs/MWCNTs/GC modified electrode showed a

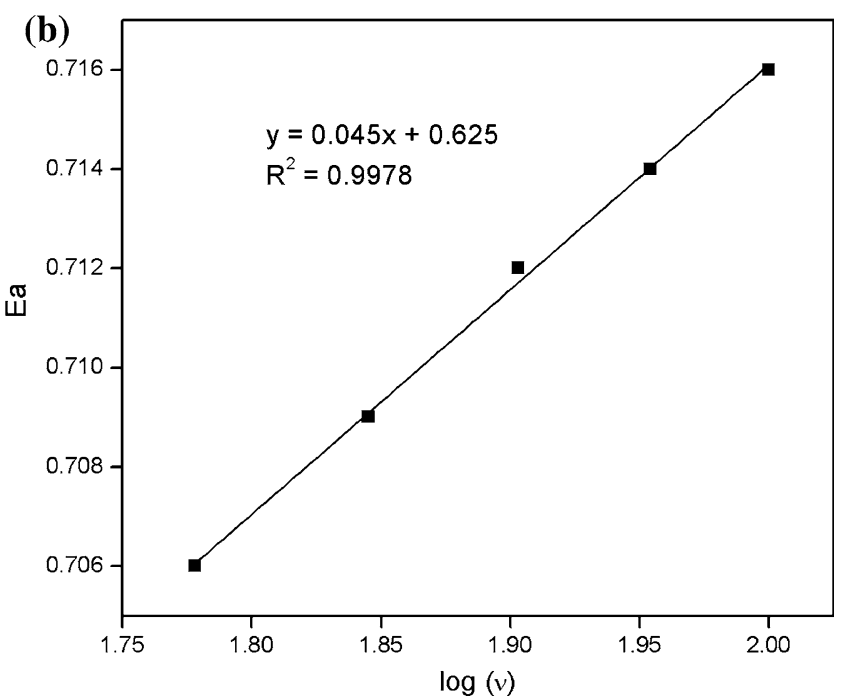

folic acid versus scan rate (v). a Calibration plot of $\log \left(i_{\mathrm{p}}\right)$ and $\log (v)$ b Calibration plot of $E_{\mathrm{a}}$ versus $\log (v)$

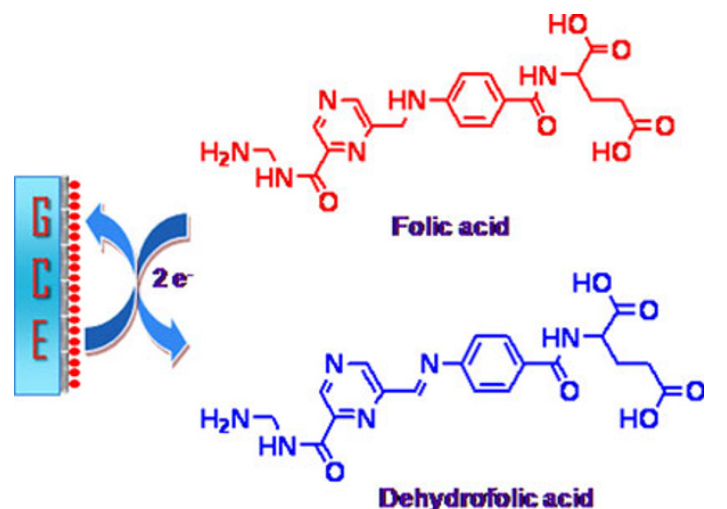

CuO Nanoleaves

Scheme $1 \mathrm{CuO} / \mathrm{MWCNTs} / \mathrm{GCE}$ modified electrode for the electrochemical oxidation of folic acid 


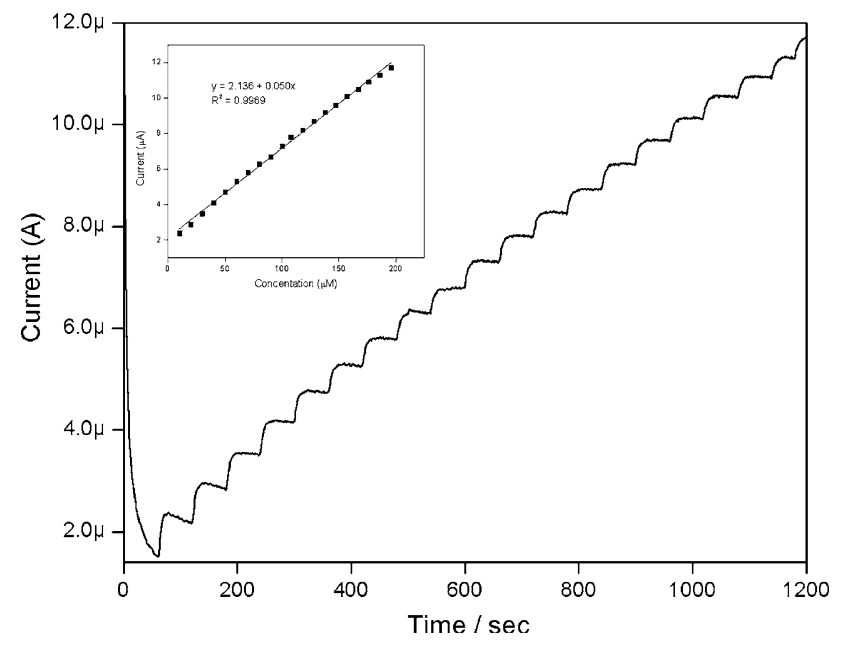

Fig. 8 Amperometric response of CuONs/MWCNTs/GCE modified electrode for the successive additions of $50 \mu \mathrm{L}$ of folic acid in a stirred 0.1 M PBS (pH 7.0). Applied potential was $+0.65 \mathrm{~V}$ versus SCE, stirring rate $300 \mathrm{rpm}$. Inset calibration plot of concentration of folic acid versus peak current

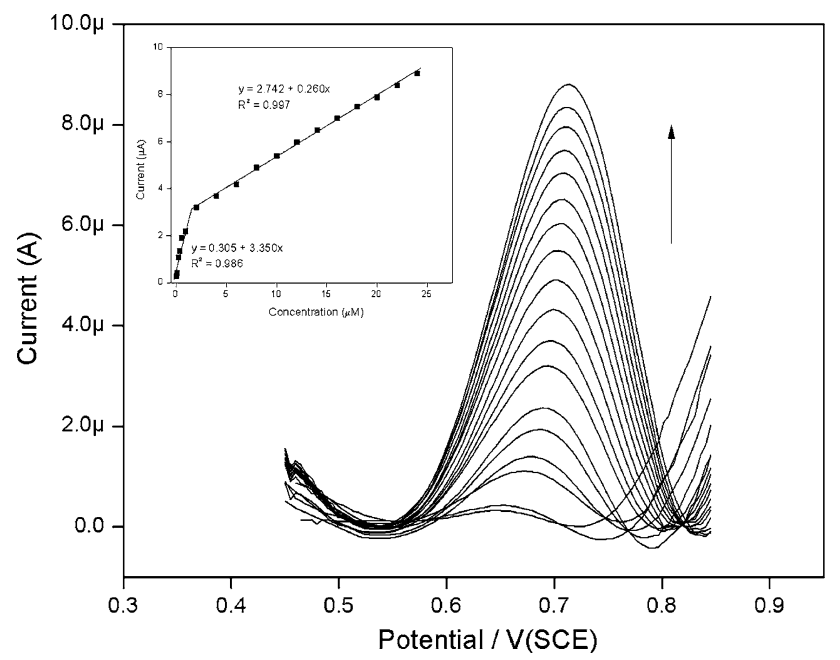

Fig. 9 DPVs (baseline corrected) of CuO/MWCNTs/GCE modified electrode in 0.1 M PBS ( $\mathrm{pH} 7.0$ ) with scan rate of $20 \mathrm{mV} \mathrm{s}^{-1}$ and pulse amplitude of $50 \mathrm{mV}$ at various concentrations of folic acid from (a) $0.01 \mu \mathrm{M}$, (b) $0.05 \mu \mathrm{M}$, (c) $0.1 \mu \mathrm{M}$, (d) $0.2 \mu \mathrm{M}$, (e) $0.3 \mu \mathrm{M}$, (f) $0.5 \mu \mathrm{M}$, (g) $0.9 \mu \mathrm{M}$, (h) $2 \mu \mathrm{M}$, (i) $4 \mu \mathrm{M}$, (j) $6 \mu \mathrm{M}$, (k) $8 \mu \mathrm{M}$, (l) $10 \mu \mathrm{M}$, (m) $12 \mu \mathrm{M}$, (n) $14 \mu \mathrm{M}$, (o) $16 \mu \mathrm{M}$, (p) $18 \mu \mathrm{M}$, (q) $20 \mu \mathrm{M}$, (r) $22 \mu \mathrm{M}$, (s) $24 \mu \mathrm{M}$. Inset calibration plot of concentration of folic acid versus peak current

steady-state current response on each addition of folic acid and attained a steady state in less than $5 \mathrm{~s}$, indicating that the $\mathrm{CuONs} / \mathrm{MWCNTs} / \mathrm{GCE}$ modified electrode has a very less response time for folic acid determination. The calibration plot (Fig. 8 (Inset) shows that the current response is linear with the folic acid concentration in the range $1 \times 10^{-5} \mathrm{M}-1.96 \times 10^{-4} \mathrm{M}\left(r^{2}=0.997\right)$ with sensitivity $0.05 \mu \mathrm{A} / \mu \mathrm{M}$ and the detection limit is $(3 \sigma)$ of $1.5 \mu \mathrm{M}$. $(\mathrm{S} / \mathrm{N}=3)$.
Differential pulse voltammetry of folic acid

To improve the sensitivity and lower the detection limit for the determination of folic acid on $\mathrm{CuONs} / \mathrm{MWCNTs} / \mathrm{GCE}$ modified electrode, differential pulse voltammetric techniques were carried out. Differential pulse voltammetry (DPV) has a discrimination against the background noise and offers much higher current sensitivity and better peak separation than cyclic voltammetry. For DPVs, the potential waveform was optimized with respect to the determination of folic acid: pulse amplitude $50 \mathrm{mV}$, with scan rate $20 \mathrm{mV} \mathrm{s}^{-1}$. Figure 9 exhibits the DPVs curves (baseline corrected) of CuONs/MWCNTs/GCE modified electrode recorded under increasing concentrations of folic acid ranging from 0.01 to $24 \mu \mathrm{M}$. The obtained linear range calibration plot [Fig. 9 (Inset)] of concentration of folic acid versus peak current results in two linear slope values. The first linear range is between 0.01 and $0.9 \mu \mathrm{M}$, and the second linear range is between 2 and $24 \mu \mathrm{M}$. A linear calibration curve was obtained for lower concentrations, whereas deviations from linearity were observed at higher concentrations. The first linear equation can be expressed as $i_{\mathrm{p}}=0.305+3.350$ (folic acid) $(\mu \mathrm{M})$. The corresponding sensitivity was obtained as $3.35 \mu \mathrm{A} / \mu \mathrm{M}$ with a detection limit $(3 \sigma)$ of $15.2 \mathrm{nM} .(\mathrm{S} / \mathrm{N}=3)$.

\section{Conclusions}

In conclusion, we have successfully synthesized $\mathrm{CuO}$ nanoleaves via a facile and simple method. The morphology of the synthesized $\mathrm{CuO}$ nanostructures revealed leaflike structure. The XRD pattern reveals the monoclinic phase of $\mathrm{CuO}$ nanostructures. The $\mathrm{CuO} / \mathrm{MWCNTs} / \mathrm{GCE}$ modified electrode exhibited good ability toward the electrocatalytic oxidation of folic acid. The sensitivity $(3.35 \mu \mathrm{A} / \mu \mathrm{M})$, detection limits $(15.2 \mathrm{nM})$ and linear response range ( 0.01 to $0.9 \mu \mathrm{M})$ for the $\mathrm{CuO} / \mathrm{MWCNTs} /$ GCE modified electrode makes it an efficient way for determination of folic acid. The present study gives an insight into the in situ growth behavior of nanoleaves and has implications in the design and development of advanced materials for biosensors.

Acknowledgments The financial support from the Department of Science and Technology, New Delhi under the scheme DST-PURSE and NCNSNT, University of Madras for characterization facilities is gratefully acknowledged by the authors.

Open Access This article is distributed under the terms of the Creative Commons Attribution License which permits any use, distribution, and reproduction in any medium, provided the original author(s) and the source are credited. 


\section{References}

Andrisano V, Bartolini M, Bertucci C, Cavrini V, Luppi B, Cerchiara $\mathrm{T}$ (2003) Analytical methods for the determination of folic acid in a polymeric micellar carrier. J Pharm Biomed Anal 32:983-989

Bailey LB, Gregory JF (1999) Folate metabolism and requirements. J Nutr 129:779-782

Choi SW, Mason JB (2000) Folate and carcinogenesis: an integrated scheme. J Nutr 130:129-132

Giron AJ, Meras ID, Pena AM, Mansilla AE, Canada FC, Olivieri AC (2008) Photoinduced fluorimetric determination of folic acid and 5-methyltetrahydrofolic acid in serum using the kinetic evolution of the emission spectra accomplished with multivariate secondorder calibration methods. Anal Bioanal Chem 391:827-835

Guo HX, Li YQ, Fan LF, Wu XQ, Guo MD (2006) Voltammetric behavior study of folic acid at phosphomolybdic-polypyrrole film modified electrode. Electrochim Acta 51:6230-6237

Kalimuthu P, John SA (2009) Selective electrochemical sensor for folic acid at physiological $\mathrm{pH}$ using ultrathin electropolymerized film of functionalized thiadiazole modified glassy carbon electrode. Biosens Bioelectron 24:3575-3580

Korolczuk M, Tyszczuk K (2007) Determination of folic acid by adsorptive stripping voltammetry at a lead film electrode. Electroanalysis 19:1959-1962

Laviron E (1978) General expression of the linear potential sweep voltammogram in the case of diffusionless electrochemical systems. J Electroanal Chem 101:19-28

Liu Y, Chu Y, Li M, Lia L, Dong L (2005) In situ synthesis and assembly of copper oxide nanocrystals on copper foil via a mild hydrothermal process. J Mater Chem 16:192-198

Liu Y, Liao L, Li J, Pan C (2007) From copper nanocrystalline to $\mathrm{CuO}$ nanoneedle array: synthesis, growth mechanism, and properties. J Phys Chem C 111:5050-5056

Osseyi ES, Wehling RL, Albrecht JA (1998) Liquid chromatographic method for determining added folic acid in fortified cereal products. J Chromatogr A 826:235-240

Poizot P, Laruelle S, Grugeon S, Dupont L, Tarascon JM (2000) Nano-sized transition metal oxides as negative-electrode materials for lithium-ion batteries. Nature 407:496-499

Reynolds E (2006) Vitamin B12, folic acid, and the nervous system. Lancet Neurol 5:949-960

Tallaksen CME, Bohmer T, Bell H (1992) Concentrations of the water-soluble vitamins thiamin, ascorbic acid, and folic acid in serum and cerebrospinal fluid of healthy individuals. Am J Clin Nutr 56:559-564
Tsai YC, Li SC, Chen JM (2005) Cast thin film biosensor design based on a nafion backbone, a multiwalled carbon nanotube conduit, and a glucose oxidase function. Langmuir 21:36533658

Umasankar Y, Ting TW, Chen SM (2011) Characterization of Poly(brilliant cresyl blue)-multiwall carbon nanotube composite film and its application in electrocatalysis of Vitamin $\mathrm{B}_{9}$ reduction. J Electrochem Soc 158:K117-K122

Vaze VD, Srivastava AK (2007) Electrochemical behavior of folic acid at calixarene based chemically modified electrodes and its determination by adsorptive stripping voltammetry. Electrochim Acta 53:1713-1721

Venkatachalam S, Zhu HW, Masarapu C, Hung KH, Liu Z, Suenaga K, Wei BQ (2009) In situ formation of sandwiched structures of nanotube $/ \mathrm{Cu}_{x} \mathrm{O}_{y} / \mathrm{Cu}$ composites for lithium battery applications. ACS Nano 3:2177-2184

Wang C, Li C, Ting L, Xu X, Wang C (2006) Application of a singlewall carbon nanotube film electrode to the determination of trace amounts of folic acid. Microchim Acta 152:233-238

Wei S, Zhao F, Xu Z, Zeng B (2006) Voltammetric determination of folic acid with a multi-walled carbon nanotubes modified gold electrode. Microchim Acta 152:285-290

Xiang JY, Tu JP, Zhang L, Zhou Y, Wang XL, Shi SJ (2010) Selfassembled synthesis of hierarchical nanostructured $\mathrm{CuO}$ with various morphologies and their application as anodes for lithium ion batteries. J Power Sources 195:313-319

Xiao F, Ruan C, Liu L, Yan R, Zhao F, Zeng B (2008) Single-walled carbon nanotube-ionic liquid paste electrode for the sensitive voltammetric determination of folic acid. Sens Actuator B 134:895-901

Yang H, Lu B, Qi B, Guo L (2011) Voltammetric sensor based on ordered mesoporous carbon for folic acid determination. J Electroanal Chem 660:2-7

Zhang BT, Zhao L, Lin JM (2008a) Determination of folic acid by chemiluminescence based on peroxomonosulfate-cobalt(II) system. Talanta 74:1154-1159

Zhang X, Wang G, Liu X, Wu J, Li M, Gu J, Liu H, Fang B (2008b) Different $\mathrm{CuO}$ nanostructures: synthesis, characterization, and applications for glucose sensors. J Phys Chem C 112:1684516849

Zhao Y, Zhao J, Li Y, Ma D, Hou S, Li L, Hao X, Wang Z (2011) Room temperature synthesis of $2 \mathrm{D} \mathrm{CuO}$ nanoleaves in aqueous solution. Nanotechnology 22:115604-115612

Zou G, Li H, Zhang D, Xiong K, Dong C, Qian Y (2006) Wellaligned arrays of $\mathrm{CuO}$ nanoplatelets. J Phys Chem B 110:16321637 